\title{
O Espaço Lúdico Terapêutico e as experimentações com adolescentes ${ }^{1}$
}

\section{The Espaço Lúdico Terapêutico and the experiences with adolescents}

\author{
Maria Cecília Galletti ${ }^{2}$
}

\begin{abstract}
GALLETTI, M. C. O Espaço Lúdico Terapêutico e as experimentações com adolescentes. Rev. Ter. Ocup. Univ. São Paulo, v. 17, n. 1, p. 18-25, jan./abr. 2006.

RESUMO: Este trabalho busca cartografar a trajetória do Espaço Lúdico Terapêutico, pela análise das experiências com adolescentes, que resultaram em mudanças significativas no modelo tradicional de intervenção em saúde mental. A adoção de uma atitude transdisciplinar, que impõe a conexão de diversos campos, construiu uma resposta que se materializou em uma estrutura assistencial complexa e flexível.
\end{abstract}

DESCRITORES: Ludoterapia. Oficinas de trabalho protegido. Crianças portadoras de deficiência/ reabilitação. Terapia ocupacional. Saúde mental. Saúde do adolescente.

\section{INTRODUÇÃO}

$\mathrm{O}$

Espaço Lúdico Terapêutico (ELT) foi criado em 1996, inserido nos projetos de assistência do Curso de Terapia Ocupacional da Universidade de São Paulo - USP. Desde o início, este serviço se caracteriza como um espaço de assistência, ensino e pesquisa, atendendo crianças e adolescentes com distúrbios globais de desenvolvimento (psicoses, autismos e deficiências mentais).

O projeto inicial propunha, segundo Brunello, idealizadora e coordenadora do serviço, a construção de um

\footnotetext{
${ }^{1}$ Esse trabalho é parte integrante da dissertação de mestrado da autora, defendido no Núcleo de Estudos da Subjetividade Contemporânea do Programa de Psicologia Clínica da PUC-SP, em 2001.

${ }^{2}$ Professora Ms do Curso de Terapia Ocupacional da Universidade de Sorocaba, Coordenadora do Centro de Convivência Parque da Previdência da Prefeitura do Município de são Paulo, Doutoranda do Núcleo de Estudos da Subjetividade Contemporânea do Programa de Psicologia Clínica da PUC-SP.

Endereço para correspondência: Rua Dardanelos, 108 apto 122B, Alto da Lapa - CEP: 05468-010. e-mail: cecig@uol.com.br
} 
lugar para brincar, um espaço que resgatasse e estimulasse o lúdico na vida das crianças "diferentes" (deficientes mentais, autistas, psicóticas), entendendo-o do mesmo modo que Rolnik (2000) posteriormente precisou tão bem: "brincar, play, onde o jogo se inventa ao mesmo tempo que suas regras, seus personagens e o lugar cambiante que cabe a cada um como jogador" (p. 5).

Quando estamos implicados na clínica de saúde mental com crianças e adolescentes, percebemos que todo o trajeto desses sujeitos que nos procuram está aprisionado pelo mapa da clínica. São perambulações exaustivas por psicólogos, psiquiatras, terapeutas ocupacionais, fonoaudiólogos, neurologistas, num circuito imenso de entrevistas, tratamentos, internações, intervenções, que mergulham essas vidas num único e restrito meio.

A propósito disto, Deleuze (1997, p. 73) diz que, “o trajeto se confunde não só com a subjetividade dos que percorrem um meio, mas com a subjetividade do próprio meio, uma vez que este se reflete naqueles que o percorrem". Então, intervir na composição de outros trajetos, na exploração de novos meios, torna-se essencial se queremos - a partir da clínica - ampliar o universo dessas crianças e adolescentes, conectá-los com outros mundos e, fundamentalmente, possibilitar um desertar o mundo restrito da saúde mental.

Nessa medida, a idéia original do projeto pode ser entendida como uma certa tendência da clínica contemporânea de apontar cada vez mais para a construção de espaços de socialização, em oposição aos espaços terapêuticos tradicionais.

Num nível mais imediato o projeto ambicionava tensionar o campo da clínica no sentido de não se colocar como mais uma terapia na vida desses sujeitos, mas se constituir como um espaço de brincadeiras, de jogos e de abertura para as crianças e adolescentes encontrarem seus próprios caminhos.

Inspirado inicialmente na idéia de instituição estourada criada por Maud Mannoni a propósito da École Experimentale de Bonneil-sur-Marne, o Espaço Lúdico, é também uma instituição que se propõe estar à margem e que

...tem em vista aproveitar e tirar partido de tudo o que de insólito surja (esse insólito que, pelo contrário, têm-se o costume de reprimir). Portanto, em vez de oferecer permanência, a estrutura da instituição oferece, sobre uma base de permanência, aberturas para o exterior, brechas de todos os gêneros (por exemplo, estadas fora da instituição)... (MANNONI, 1977, p. 79)

Segundo essa autora, “...o essencial da vida desenrola-se em outra parte - num trabalho ou num projeto no exterior..." (idem).

\section{O espaço do ELT e as intersecções}

O espaço físico projetado para as atividades do Espaço Lúdico é composto por salas do Centro de Docência e Pesquisa em Terapia Ocupacional que servem tanto para o atendimento às crianças e adolescentes quanto para laboratório de atividades dos alunos do curso de TO. A equipe é constituída por terapeutas ocupacionais.

Para esta nova prestação de assistência, no início do projeto, os pacientes vinham prioritariamente da própria "comunidade USP": outros serviços de assistência do curso de TO, serviços de assistência do curso de Fonoaudiologia e Fisioterapia, que funcionam no mesmo prédio, e a PréEscola Terapêutica Lugar de Vida (instituição parceira em algumas atividades com adolescentes). Após alguns meses de funcionamento, o ELT passou a receber também encaminhamentos de outros serviços da região e de outras instituições de São Paulo e de Osasco, município situado nas proximidades da Cidade Universitária.

A partir de entrevistas ligeiras, que buscavam investigar o lugar da brincadeira na vida das crianças, e a que denominávamos acolhida, alguns grupos foram criados com o objetivo primeiro de se constituírem como espaços complementares e de alternância com os tratamentos: um lugar para a criança "estranha" ir brincar.

Entretanto, com o passar do tempo, começamos a receber crianças e adolescentes gravemente comprometidos, provenientes das mais diversas regiões de São Paulo.

As entrevistas iniciais realizadas pelos terapeutas da equipe, em que as famílias relatavam dificuldades de encontrar lugares que se dispusessem a atender seus filhos, levaram ao surgimento, no ELT, de várias estratégias isoladas de intervenção, digamos mais terapêuticas. Assim, um atendimento individual aqui, uma visita domiciliar ali, um grupo de pais... várias situações que, a todo momento, obrigavam-nos a colocar em questão o funcionamento institucional e a reelaborar a proposta inicial.

Era uma encruzilhada: como não se tornar um ambulatório de especialidades, com terapias específicas de TO e continuar a ser um lugar para brincar?

Para nós da equipe, essa sempre foi uma questão fundamental, já que tínhamos como parâmetro não sermos engolidos por um certo referencial clínico. Ou, dizendo de outra forma, nosso objetivo era ocupar na clínica um lugar de deslocamento dela própria.

Desta forma, o caminho foi buscar um entre o ambulatório e o lugar de brincar, construindo um espaço onde coubessem as terapias e também as brincadeiras, jogos, passeios, festas e oficinas, para que a clínica pudesse ser fabricada no coletivo das ações, e as intervenções ao 
invés de serem previamente moldadas, pudessem se constituir como catalisadores existenciais, com estratégias singulares em constante mutação.

Com isso, a montagem da assistência no ELT ganhou uma configuração articulada por três eixos fundamentais, a saber:

1. Intervenções com crianças e adolescentes:atendimentos domiciliares, grupos, oficinas, atendimentos domiciliares e acompanhamento terapêutico;

2. Intervenções com as famílias: atendimentos processuais, grupos, oficinas, atendimentos pontuais e orientações;

3. Intervenções com outras instituições que alternam com o tratamento: escolas, creches e outros tratamentos.

Essa montagem institucional foi ancorada na crença de que as crianças e adolescentes assistidos por nós não necessitavam apenas de atendimentos específicos de TO ou de outra especialidade, mas de um corpo institucional e de dispositivos diversos de sustentação, como dobras terapêuticas no tecido social, que lhes abrissem possibilidades de alternância, isto é, ir de um lugar para outro, comportar novas experimentações, habitar novos lugares, situações difíceis para sujeitos marcados por histórias de psicoses, autismos ou deficiências mentais graves.

Assim, o ELT é um lugar multifacetado, rico em aspectos que colocam questões complexas. Neste trabalho, a proposta é problematizar apenas um desses dispositivos de intervenção implementados na montagem desse serviço, ou seja, as oficinas com adolescentes.

\section{As oficinas no ELT: da técnica ao dispositivo}

As oficinas no ELT são formuladas na intersecção instituição/campo social, isto é, nas intervenções que exigem que se pense para fora da instituição ou, melhor dizendo, nesses processos em que intencionamos fomentar trânsitos, movimentos e passagens diversas, dos pacientes por outros circuitos sociais.

Atualmente sua diretriz está presente em quase todas as instituições que trabalham na clínica da saúde mental. Os movimentos institucionais das últimas décadas foram categóricos na afirmação sobre a importância da abertura das instituições para a esfera social. Mas como fazer isso sem cair na armadilha de que existe um indivíduo ou um grupo a ser incluído? Como não entender o campo social de um lado e a clínica de outro? Como não hierarquizar, e continuar nas intervenções-promessas?

Nossa perspectiva com o trabalho das oficinas é inovadora. Consideramos que as oficinas não são meros instrumentos aplicáveis a serviço de um projeto, mas um espaço que mobiliza novas práticas e outras formas de organização. Assim, tomando-as em sua dimensão de dispositivos, acreditamos que elas possam se constituir como uma mediação entre os vários aspectos heterogêneos de uma dada situação. Como bem aponta Barros (1997, p. 187), "com isso não estamos nos referindo a qualquer tipo de intermediação entre totalidades (o social e o indivíduo)".

Essa autora afirma que trabalhar na filosofia dos dispositivos é ultrapassar a dimensão das dicotomias que se estabelecem entre o indivíduo e o social, pois articular heterogêneos é constituir um espaço para além dos elementos já constituídos.

Foucault (1994), esclarece que o termo dispositivo aponta para três vetores: o caráter de rede do dispositivo (o dispositivo estabelece ligação entre os elementos heterogêneos: discurso, instituição, as leis, os regulamentos, enunciados científicos, proposições filosóficas); a natureza da ligação (os elementos podem ser discursivos ou não e existe um jogo de mudança de posição entre eles); e ainda o caráter de estratégia que tem por função responder a uma urgência.

Aponta, ainda, que

...o dispositivo se constitui como tal e permanece dispositivo, na medida em que ele é lugar de um duplo processo: processo de sobredeterminação funcional, de um lado, já que cada efeito, positivo ou negativo, desejado ou não, vem entrar em ressonância, ou em contradição com os outros, e obriga a um reajustamento dos elementos heterogêneos que apareceram. É um processo perpétuo de preenchimento estratégico... (FOUCAULT, 1994, p. 299).

Mas melhor entendimento dessa posição sugiro nos lançar a uma viagem pelo dispositivo oficinas. Antes, porém, considero importante diferenciar sucintamente as noções de técnica e dispositivo que estamos utilizando aqui, já que esses termos são muitas vezes tomados como sinônimos. Técnica é aqui vista como um instrumento, um material aplicativo a uma dada situação. O dispositivo, ao contrário, nasce $n a$ situação como dobra estratégica da própria experiência.

\section{Os adolescentes e as experimentações de "trabalho"}

Falar de "experimentações de trabalho com adolescentes" exige o esclarecimento prévio sobre a relação entre educação e trabalho na infância e adolescência.

Estou chamando de "trabalho com adolescentes", 
experimentações ligadas ao aprendizado de um ofício. Especialmente no que diz respeito aos adolescentes, os processos de profissionalização e inserção no campo do trabalho, conforme indica a legislação vigente (Lei 8069, de 13/07/1990, Estatuto da Criança e do Adolescente), não devem impedir ou competir com o processo de escolarização. Ao contrário, tem sido orientação das políticas de atenção à infância e juventude, focalizar a educação e a escolarização nos processos de abertura ao mundo do trabalho. Na Constituição brasileira, a preparação para o ingresso no trabalho é o terceiro alvo da educação, sendo esta preparação entendida como aquisição de habilidades básicas e específicas de gestão necessárias para a inserção na vida produtiva.

De outro lado, as características contemporâneas do mundo do trabalho têm desafiado os que trabalham com profissionalização de adolescentes e jovens a redimensionarem os objetivos da educação.

Assim, temos nos ancorado para o desenvolvimento deste projeto com adolescentes, para além da compreensão do trabalho na sua dimensão de inclusão e produção de subjetividade, também da compreensão da Educação tal como formulada pela Unesco (1998): a educação deve se estender ao conjunto da experiência humana, abraçando quatro diferentes eixos: ser, conviver, aprender e fazer, ou seja, o desenvolvimento das competências: pessoal, social, cognitiva e operativa.

O eixo do fazer, privilegiado nas oficinas com os adolescentes, é entendido

“...de uma maneira ampla, não apenas para adquirir uma qualificação profissional, mas competências que tornem a pessoa apta a enfrentar numerosas situações e trabalhar em equipe. Mas também, aprender a fazer, no âmbito das diversas experiências sociais ou de trabalho que se oferecem aos adolescentes, quer espontaneamente, quer formalmente..." (UNESCO, 1998, p. 101-102).

Tornada clara a concepção assumida pelo ELT sobre a relação educação/trabalho na adolescência, cabe apontar que as atividades nessa área iniciaram-se em 1996, numa parceria realizada por dois docentes do curso de Terapia Ocupacional da USP, comprometidos com a implantação de atividades clínicas nessa universidade, com a Pré-Escola Terapêutica Lugar de Vida, do Instituto de Psicologia da USP.

Num primeiro momento, o pedido do Lugar de Vida para o curso de Terapia Ocupacional foi de um projeto de oficinas para as crianças crescidas daquela instituição, isto é, para pré-adolescentes ou já adolescentes com problemas emocionais graves, que se viam às voltas com a questão da inserção, não somente no âmbito escolar. A Pré-Escola Lugar de Vida, segundo Cristina Kupfer, coordenadora do serviço, é uma instituição organizada para atender crianças e tem como objetivo final a inserção escolar, e por isso se encontrava sem ferramentas para lidar com as novas questões para as quais a "carreira de exclusão" daquelas crianças apontava, as relacionadas à inserção no mundo do trabalho.

Assim, o Lugar de Vida, solicitava projetos cujo referencial não fosse mais a infância mas a possibilidade de inscrição dessas crianças em uma outra fase da vida, a adolescência, considerado um período difícil, de indefinições, crises, rearranjos e descobertas. Particularmente com crianças marcadas por histórias de psicose ou autismos, isto se torna ainda mais problemático, sobretudo porque esse período de transição ainda está quase sempre submetido a enredos de infantilização.

Havia aí então uma questão complexa: tanto as crianças, quanto as famílias e as instituições envolvidas estavam às voltas com a problemática da exclusão social que repercutia na questão do trabalho. A chegada da adolescência leva as famílias a se preocuparem com o problema da autonomia e sobrevivência financeira dos filhos e assim passam a demandar das instituições clínicas e educacionais, o aprendizado de um ofício. Trata-se de uma questão espinhosa para todos que se propõem a atuar na saúde mental: por um lado, sabemos que o trabalho é uma importante ferramenta de inserção social, mas por outro sabemos também que a exclusão do mercado atinge atualmente proporções que vão muito além da questão da saúde.

No entanto, ainda que a problemática do mercado de trabalho extrapole o campo da saúde mental, na clínica com adolescentes e adultos, muitas vezes os terapeutas (e principalmente os terapeutas ocupacionais) estarão envolvidos com a preparação para o trabalho. Por isso, a problematização das práticas de inclusão social, significa não reduzi-las a meras estratégias de adaptação a realidades dadas, mas, como diz Lima e Brunello (2000, p. 76), visando "buscar o sentido último do trabalho clínico, em sua vertente de prática social, como criação de agenciamentos coletivos e de territórios compartilhados".

Assim, o trabalho de terapia ocupacional, em análise neste estudo, começou com um grupo de seis adolescentes, com idades entre 12 e 16 anos, acontecendo uma vez por semana no laboratório de $\mathrm{TO}^{(1)}$.

\footnotetext{
(1) Esse trabalho teve continuidade nos anos seguintes e no final do ano 2000 eram atendidas 8 crianças com idades entre 11 e 18 anos.
} 
As terapeutas que iniciaram o trabalho - Elizabeth Araújo Lima e Maria Ines Britto Brunello - relatam que o começo da experiência foi vivido como um período de reconhecimento de um novo espaço (já que não eram atendidos no mesmo espaço do Lugar de Vida) e de uma nova forma de trabalhar. As pias, bancadas e ferramentas do laboratório de TO incluíram esses jovens na atmosfera das oficinas, de forma que, quando chegavam à TO, costumavam dizer que tinham vindo para trabalhar.

Naquele período, várias atividades foram desenvolvidas com o grupo, buscando experimentar e perscrutar o foco de interesse grupal. Essas atividades utilizavam materiais diversos (tintas, pincéis, jornais, revistas, papéis, colas, tesouras, culinária, madeira) e aquelas que faziam uso de madeira pareciam interessar mais ao grupo. Por isso, iniciamos com eles, a oficina de marcenaria.

\section{A oficina de marcenaria}

Nesta fase, algumas situações ainda me tomam de assalto, pois foi ali na oficina de marcenaria que iniciei meu trabalho no ELT. Penso que para um terapeuta, entrar num grupo-oficina de psicóticos é quase como um elefante, entrando numa loja de cristal. Assim, foi preciso muita delicadeza para chegar e conhecer cada um dos personagens daquele grupo.

Lembro-me de um adolescente do grupo que solitariamente fazia e refazia seu caminhão de madeira. Era muito difícil para ele aceitar qualquer interferência do grupo na sua atividade. Durante semanas, observei aquele garoto com seu caminhão que era construído e desconstruído a cada encontro.

Num desses encontros, percebi que os pregos que ele usava para juntar as madeiras eram menores que a largura delas. Em alguns encontros, no ritual da chegada, onde era realizada a preparação para o trabalho, sugeri novos pregos, maiores e mais largos que os outros, colocando os potes maiores junto ao seu projeto de caminhão. Foram necessários vários encontros para Luís retirar os pregos pequenos e usar o material adequado para seu trabalho.

Num trabalho com oficinas, em que se valoriza a produção como um certo aprendizado de ofício, é importante a escolha certa dos materiais, o uso das ferramentas e a combinação deles. A oficina de marcenaria impunha a todos os participantes, por exemplo, o conhecimento das ferramentas e materiais, saber quando usar o serrote ou a serra elétrica, quando usar pregos ou cola de madeira. Tudo isso fazia com que a oficina não fosse um jogo de faz-deconta. Para os adolescentes, pedir o uso da morsa ou de um alicate era carregado de sentido, no que eram totalmente incentivados pelos terapeutas, não para imitar jogos papai e filhinho ou coisa parecida, mas para que aqueles materiais tivessem sua real potência de engendrar a realidade de uma marcenaria na vida daqueles sujeitos.

Esses encontros eram marcados por uma vivência intensa de cada usuário com seu projeto. Eram casas, caminhões, postos de gasolina, televisões. O uso de materiais, ferramentas e espaço físico de verdade, tinha por si só a potencialidade de marcar a entrada desses adolescentes no reino do trabalho, não de um trabalho qualquer, mas ali era como se nos transportássemos para o mundo de uma oficina de marcenaria, com livros que contavam as histórias de antigos marceneiros, atlas de nomes de ferramentas, e principalmente onde o aprendizado, a concepção e a execução se realizavam conjuntamente.

Isso não quer dizer que havia nesse projeto imitação ou cópia de um modelo preestabelecido da atividade de marcenaria, mas a produção daqueles encontros aproximava os dois reinos: oficina de marcenaria e trabalho de marceneiro transpondo a barreira que normalmente separa as experimentações clínicas das experimentações da vida comum.

Esses projetos eram naquele momento quase sempre realizados individualmente, mas isso é também o que acontece em quase toda marcenaria, onde os marceneiros trabalham cada um com seu projeto: uma cozinha, um armário embutido, um gabinete de banheiro. O coletivo dessa experiência não se dá pelo trabalho de várias pessoas num único projeto, mas pela possibilidade de intercambiar experiências. Isto deve ser valorizado e até fomentado pela clínica contemporânea, essa que se deixa realmente afetar pela problemática da inserção social e pela construção não de enredos individualizantes mas de modos diversos de subjetivação.

Conforme apontam Guattari e Rolnik (1996),

os processos de subjetivação... não são centrados em agentes individuais (...) nem em agentes grupais (...) Implicam o funcionamento de máquinas de expressão que podem ser tanto de natureza extrapessoal, extraindividual, (...) quanto de natureza infra-humana, infrapsíquica, infrapessoal... (p. 31).

Nesse período, um projeto foi comum a todos os participantes: um campo de futebol de madeira para jogo de futebol de botão. Isso aconteceu não porque consideramos atividade grupal aquela que se realiza por todos juntos, mas porque nessa ocasião nos encontrávamos em plena Copa do Mundo e os adolescentes desse grupo, como tantos outros, viram-se envolvidos em disputas, formação de time, escolha de parcerias e torcidas. 
Ora, nesse sentido, o projeto do campo de futebol foi um dispositivo da oficina de marcenaria, pois nasceu como dobra estratégica da experiência da oficina, que não estava alheia à pulsação social. Essa produção coletiva, realizada pelo contágio provocado pela Copa do Mundo e pela aliança grupal, produziu novos sentidos para os participantes do grupo.

No final de um ano de realização dessa oficina, outros interesses começaram a se insinuar para esses adolescentes: outros projetos como artes plásticas, esportes, culinária e também o desejo de circular sozinho pela cidade. Isso gerou o desfazimento do projeto marcenaria.

O término dessa oficina não foi vivido na instituição como "uma experiência que não deu certo", o que geralmente ocorre quando findam os projetos, ao contrário, foi entendido que ela atingiu o ponto de sua própria abolição, necessária para abrir outros caminhos e permitir outras conexões.

Após esse período, alguns adolescentes que concluíram seus períodos de escolarização, foram desenvolver, na condição de aprendizes, projetos de trabalho remunerado - de caráter informal, geralmente em oficinas de alfaiataria, costureiras e pequenas confecções - e outros continuam nas oficinas da TO em outros projetos.

\section{Desdobramentos: contaminando a cidade}

Com o encerramento da oficina de marcenaria, iniciamos com o grupo outras atividades que nos pareciam também importantes para ampliar a circulação dos adolescentes pela esfera social, pois percebemos que a experiência social desses sujeitos está permanentemente atravessada pelo campo da saúde mental: suas saídas estão sempre vinculadas a atividades de tratamentos.

Assim, uma vez que nosso compromisso com a clínica têm sido o de praticá-la nas bordas e na intersecção com outros planos, passamos desde então a experimentações diversas quanto a saídas das crianças e adolescentes sem o acompanhamento dos pais, incentivando vivências em situação do cotidiano, como por exemplo, grupo de culinária, jogos de rua e jogos esportivos em quadras da cidade.
Tais empreendimentos foram despertados pelo contato desses adolescentes com outros jovens estudantes da USP que transitam pelos corredores dos atendimentos, fazem e vendem "comidinhas" nos intervalos de aulas, e freqüentam as quadras e centros esportivos na cidade universitária. Nessas atividades de circulação, fomos a museus, lanchonetes da USP, quadras e parques públicos municipais.

Nosso objetivo é, portanto, oferecer aberturas diversas e criar situações reais de encontro com o outro. Assim, os terapeutas acompanham todo o movimento grupal, abrindo brechas, intervindo quando necessário, mas principalmente criando um espaço de referência, um ponto de atração e sobretudo um campo de solidariedade, entendida aqui no seu sentido ativo como nos convoca Rolnik. Para essa autora, a solidariedade não consiste apenas em relacionarse com o outro pelo simples respeito civil, politicamente correto, mas também em desejar a singularidade do outro, expor-se à alteridade e contaminar-se com o outro (ROLNIK).

Uma característica muito interessante desse trabalho é a sua potência em promover estranhamentos em todos os que se expõem a ele. Numa dessas saídas com o grupo, fomos passear no Parque da Previdência (localizado nas proximidades da USP), onde encontramos um grupo de pessoas fazendo ginástica. Quando sentamos num banco e ficamos observando a atividade, dois garotos do nosso grupo se juntaram ao grupo de ginástica desenvolvendo passos de capoeira.

Sentados com o restante do nosso grupo, fomos então surpreendidos por uma senhora que se dizia terapeuta do grupo de ginástica e que a atividade fazia parte da programação do Centro de Convivência do Parque da Previdência, Cecco - Serviço de Saúde Mental da Prefeitura do Município de São Paulo, naquele momento gerenciado pelo $\mathrm{PAS}^{(2)}$. Ela pedia aos responsáveis por nosso grupo que retirassem os garotos dali pois eles estavam atrapalhando a atividade que ela estava realizando com "seus deficientes".

Para nosso grupo, sobretudo para os terapeutas, esse acontecimento foi muito desestabilizador, por isso tomado como um analisador ${ }^{(3)}$.

\footnotetext{
(2) O PAS (Plano de Assistência à Saúde) foi implementado pelo governo do prefeito Paulo Maluf (1992-1996). Este plano transferiu a gerencia das unidades de saúde da PMSP para cooperativas privadas e desmantelou todo o sistema público de saúde da cidade de São Paulo. Fui coordenadora desse serviço, até a implantação do PAS na região (maio de 1996), quando por determinação do prefeito Paulo Maluf, fui exonerada da função, transferida sumariamente para outra Secretaria e proibida de retornar àquele local de trabalho. Após o término do PAS retomei a gerencia deste serviço, cargo que ocupo até o momento).

(3) O termo analisador é utilizado aqui como uma potência de colocar em análise o estabilizado, é aquilo que rompe com o instituído, produzindo outras singularidades (BAREMBLITT, 1992).
} 
$\mathrm{Na}$ atividade em "grupo" coordenada por aquela senhora, a convivência é tomada no seu sentido mais negativo. A questão da diferença aqui se revela por um modo cultural de manutenção das identidades, sem produzir modificações nos territórios subjetivos constituídos. Essa situação mostrou claramente as diferentes concepções de clínica que estavam em jogo no encontro das duas instituições (ELT x Cecco-PAS) e os efeitos dessas diferenças no modo de trabalho com os usuários. Para nós do ELT, as saídas da instituição e os passeios acompanhados não têm como objetivo a adaptação a um certo modelo de circulação, nem a domesticação da "estrangeiridade", mas a possibilidade de desfazimento das identidades: "normais", "loucos", "deficientes" e "terapeutas".

Naquele dia pudemos observar a vida pulsando em cada ato dos jovens que acompanhávamos. A "alegria" tomava corpo nos movimentos de capoeira, danças diversas, risadas, cantos, conversas, que se contrapunham aos movimentos "tristes" e estereotipados dos participantes daquela aula de ginástica. Essa é, a meu ver, a diferença fundamental das propostas de intervenção que ali se apresentavam: a primeira, da qual partilhamos, visa trabalhar com a vida e portanto com a singularidade dos modos de existência e a segunda em que o trabalho se dirige especificamente aos processos de normalização.

Nesses passeios que fazemos pela cidade, verificamos a pertinência da intervenção de um guarda de museu para que os meninos não coloquem as mãos nas obras, ou de um caixa de lanchonete que pergunta para alguém que "empaca" na sua frente, se vai resolver ou não o que quer comprar, já que ele tem mais o que fazer na vida. Estas aproximações provocam vibrações em ambos os lados. São afetos que exercem pressões e que obrigam todos a se recriarem.

Consideramos que essas intervenções que não vêm do campo "psi” são muitas vezes extremamente eficazes, porque comportam por si só todo o repertório de sentido, isto é, não precisam de intermediários. Por isso devemos cada vez mais oferecer aos usuários a possibilidade de habitar outros lugares, ouvir línguas estrangeiras, essas que são alheias ao campo "psi", até porque a vida se desenrola sempre alhures. Nesta perspectiva, o que permanece como instituição deve ser somente uma estratégia de extroversão, uma instituição que se ofereça tal como uma "centrífuga" (4), um lugar onde se vai para sair de si e ir para outros lugares.

Acredito que isto é fundamental, para que nós terapeutas estejamos atentos a que a instituição ofereça saídas para fora dela mesma, pois só aí estaremos contribuindo para uma real desinstitucionalização dos nossos usuários.

E aqui utilizo o termo desinstitucionalização num sentido ético e político; como abertura para a vida, para a liberdade de misturas e para a não adesão absoluta a qualquer sistema de referência.

GALLETTI, M. C. The "Espaço Lúdico Terapêutico" and the experiences with adolescents. Rev. Ter. Ocup. Univ. São Paulo, v. 17, n. 1, p. 18-25, jan./abr. 2006.

\begin{abstract}
This work's aims to map the path of the Espaço Lúdico Terapêtico, through the analyses of the experiences with adolescents, that had results in significant changes in traditional intervention model in mental health. The adoption of a transdisciplinary attitude, that always impose a connection with several domains, had built an answers that had materialized in a complex and flexible care structures.
\end{abstract}

KEY-WORDS: Play therapy. Sheltered workshops. Disabled children/rehabilitation. Occupational therapy. Mental health. Teen health.

\title{
REFERENCIAS
}

BAREMBLitT, G. F. Compêndio de análise institucional e outras correntes. Rio de Janeiro: Rosa dos Tempos, 1992.

BARROS, R. D. B. de. Dispositivos em ação: o grupo. In: SILVA, A. do E. et al. (Org.). SaúdeLoucura 6 - Subjetividade: questões contemporâneas. São Paulo: Hucitec, 1997.

DELEUZE, G. Crítica e clínica. Trad. Peter Pál Pelbart. São Paulo: Ed. 34, 1997.

FOUCAULT, M. Dits et ècrits. Paris: Gallimard, 1994. v.3.

(4) Esta idéia preciosa me foi sugerida pelo Prof. Luís Orlandi por ocasião do exame de qualificação da minha dissertação de mestrado. 
GALLETTI, M. C. Oficina em saúde mental: instrumento terapêutico ou intercessor clínico? Goiânia: Editora da UCG, 2004.

GUATTARI, F.; ROLNIK, S. Micropolítica: cartografias do desejo. 4a. ed. Petrópolis: Vozes, 1996.

LIMA, E.; BRUNELLO, M. I. B. Oficina de marcenaria: uma experiência de criação de mundos. Rev. Latinoamer. Psicopatol. Fundamental, v. 3, n. 1, mar. 2000.

MANONNI, M. Educação impossível. Trad. Álvaro Cabral.
Rio de Janeiro: Francisco Alves, 1977.

ROLNIK, S. Os mapas movediços de Öyvind Fahlström. In: Öyvind Fahlström. Catálogo da retrospectiva da obra do artista nos Museu d'Art Contemporani de Barcelona (Espanha, 2000), Malmö Konsthall (Suécia, 2001), Baltic Center for Contemporary Art (Inglaterra, 2001), Bienal de São Paulo (Brasil, 2001).

UNESCO. Relatório Jacques Delors: educação, um tesouro a descobrir. Relatório para a Unesco da Comissão Internacional sobre Educação para o século XXI. São Paulo: Cortez/Unesco/ MEC, 1998.

Recebido para publicação: 13/12/2005

Aceito para publicação: 24/01/2006 